\title{
Percutaneous mitral valvotomy in rheumatic mitral stenosis: a new approach
}

\author{
P. COMMEAU, G GROLliER, B HURET, J P FOUCAULT, J C POTIER \\ From the Service de Cardiologie, Centre Hospitalier Universitaire de Caen, Avenue de la Côte de Nacre, \\ Caen, France
}

SUMMARY Three patients with rheumatic mitral stenosis were treated with percutaneous mitral valvotomy. A Brockenbrough catheter was advanced transseptally into the left atrium and then into the left ventricle over a long guide wire. An angle wire loop retriever was advanced through a $10 \mathrm{Fr}$ straight catheter via the femoral artery into the left ventricle. The retriever was used to catch the flexible end of the long guide wire. This end of the long guide wire was then drawn out of the right femoral artery by the retriever through the straight catheter. The straight catheter was left in the descending aorta; the Brockenbrough catheter was removed and a $7 \mathrm{Fr}$ balloon catheter was introduced percutaneously over the long guide wire through the femoral vein. This balloon catheter was used for interatrial septal dilatation and right femoral venous dilatation. In two patients this catheter was replaced over the long guide wire with a 9 Fr Schneider-Medintag Grüntzig catheter $(3 \times 12 \mathrm{~mm}$ diameter when inflated) and in the other by a Mansfield $(18 \mathrm{~mm}$ diameter when inflated). The procedure was well tolerated in these three patients and there were no complications. Haemodynamic function improved, there was appeciable decrease in dyspnoea, and exercise tolerance was increased.

This procedure has several advantages: the balloon is more easily positioned through the mitral valve; the stability of the balloon during inflation is improved by traction at both ends of the long guide wire; and there is the option of rapidly exchanging one balloon for a larger one over the long guide wire. This technique seems to be less arrhythmogenic and results in less blood loss because manual compression of the femoral vessels after the procedure is easier.

Closed or open mitral valvotomy are commonly used to treat mitral valve stenosis and the long term results are good. ${ }^{1-3}$ Recently several workers have proposed percutaneous balloon dilatation as a treatment of valve stenoses, such as congenital pulmonary stenosis and congenital aortic stenosis, in children..$^{4-6}$ The results of balloon dilatation of the mitral valve are also good in adults and young patients with rheumatic valve stenosis. ${ }^{7-12}$ Various techniques have already been used to achieve valvotomy. We describe a new technique for percutaneous balloon mitral valvotomy that we used in three cases of rheumatic mitral valve stenosis.

\section{Patients and methods}

CASE 1

A 44 year old white man with chronic rheumatic

Requests for reprints to $\mathrm{Dr} P$ Commeau, Laboratoire d'Hémodynamique, Service de Cardiologie, CHU Côte de Nacre, 14033 Caen Cedex, France.

Accepted for publication 25 February 1987 mitral valve disease was admitted to our hospital with increasing dyspnoea despite treatment with diuretics and vasodilators. He had a murmur indicating mitral stenosis without regurgitation. The electrocardiogram showed a sinus rhythm with left atrial hypertrophy. Echocardiographic studies revealed severe mitral stenosis with moderate thickening of the mitral leaflets and subvalvar apparatus. There was evidence of moderate enlargement of the diameter of the atrium $(5 \mathrm{~cm})$ but ventricular size and function were normal. Cardiac catheterisation was performed to evaluate the severity of the mitral stenosis. The mean gradient across the mitral valve during diastole (calculated by planimetry) was $23 \mathrm{~mm} \mathrm{Hg}$; cardiac output (calculated by thermodilution) was $4.81 / \mathrm{min}$, and the calculated area of the mitral valve was $1.13 \mathrm{~cm}^{2}$. Left ventriculography showed well preserved ventricular function and no evidence of mitral regurgitation. The results of coronary angiography were normal. A pulmonary arteriogram with venous phase showed moderate enlargement of the left atrium and no evidence of 
atrial mural thrombus. Surgical mitral valve commissurotomy was recommended but the patient refused. Treatment by percutaneous dilatation was then suggested. The patient agreed to the procedure and gave his informed consent.

\section{CASE 2}

A 62 year old woman who had had rheumatic valve disease since 1938 was admitted to our hospital for evaluation of mitral valve stenosis. For 24 months exertional dyspnoea had become progressively worse despite treatment with diuretics and vasodilators. There was a loud first heart sound with an opening mitral snap and a faint diastolic rumble of mitral stenosis. There was no evidence of pulmonary arterial hypertension. The electrocardiogram showed atrial fibrillation. Echocardiographic studies showed moderate mitral stenosis but the leaflets and subvalvar apparatus were not thickened. The diameter of the left atrium was enlarged $(5.4 \mathrm{~cm})$ but there was no evidence of mitral thrombus. Cardiac catheterisation showed a diastolic mean gradient across the mitral valve of $5 \mathrm{~mm} \mathrm{Hg}$, a cardiac output (calculated by thermodilution) of $1.7 \mathrm{l} / \mathrm{min}$, and a calculated mitral valve area of $0.60 \mathrm{~cm}^{2}$. An isoprenaline test was carried out. When the heart rate was 170 beats/min, the diastolic mean gradient across the mitral valve was $36 \mathrm{~mm} \mathrm{Hg}$ and the calculated mitral valve area was $0.31 \mathrm{~cm}^{2}$. Left ventriculography showed good ventricular function without evidence of mitral regurgitation. Coronary angiography was normal. The pulmonary arteriogram with venous phase showed a considerably enlarged left atrium and no evidence of atrial mural thrombus. After the procedure was discussed and explained the patient gave informed consent to percutaneous balloon dilatation of the mitral valve.

CASE 3

A 60 year old woman was admitted to our hospital with severe exertional dyspnoea and paroxysmal atrial fibrillation. There was a loud first heart sound followed by a grade $2 / 6$ pansystolic murmur indicating mitral regurgitation. The pulmonary component of the second heart sound was increased and there was an opening snap and a diastolic rumble indicating mitral stenosis. The electrocardiogram showed sinus node rhythm with occasional premature supraventricular complexes, incomplete right bundle branch block, and hypertrophy of both atria. Cardiac fluoroscopy showed calcifications of the mitral valve. Cross sectional echocardiography showed severe mitral stenosis and calcification of the two leaflets and mitral annulus. There was no evidence of enlargement of the diameter of the left atrium $(4 \cdot 2 \mathrm{~cm})$. Left ventricular function was well preserved and the right atrium and right ventricle were enlarged. The patient was treated with frusemide, a vasodilator, amiodarone, and an anticoagulant. Cardiac catheterisation showed pulmonary hypertension (systolic pulmonary pressure 115 , diastolic 37 , mean $62 \mathrm{~mm} \mathrm{Hg}$ ). The mean diastolic gradient across the mitral valve was $27 \mathrm{~mm}$ $\mathrm{Hg}$, the cardiac output (thermodilution technique) was $3.41 / \mathrm{min}$, and the calculated mitral valve area was $0.54 \mathrm{~cm}^{2}$. Left ventriculography showed normal left ventricular function with moderate mitral valve regurgitation. Coronary angiography was normal. After the procedure was discussed and explained the patient gave informed consent to percutaneous balloon dilatation of the mitral valve.

\section{Balloon dilatation procedure}

Patients were premedicated with $30 \mathrm{mg}$ of oral diazepam 30 minutes before the procedure. A 8 Fr pigtail catheter was advanced from the left femoral artery into the ascending aorta. The right heart was catheterised from the left femoral vein with a triple lumen Swan-Ganz catheter. Right heart oximetry series were performed. A $10 \mathrm{Fr}$ straight catheter (Cook) was advanced into the left ventricle from the right femoral artery. A $8 \mathrm{Fr}$ Brockenbrough catheter (USCI) was inserted into the left atrium through the right femoral vein by the transseptal catheter technique. Heparin (10000 UI) was given. The Brockenbrough catheter was advanced into the left ventricle over a long guide wire (AHS: $400 \mathrm{~cm}$ long, 0.035 inch diameter). Then an angle wire loop retriever (Cook: $100 \mathrm{~cm}$ long, with a loop $25 \mathrm{~mm}$ diameter formed by 0.015 inch braided cable) was advanced through the $10 \mathrm{Fr}$ straight catheter. The retriever was placed in the left ventricle and was used to catch the flexible end of the long guide wire. The retrieved end of the long guide wire was drawn out of the right femoral artery through the straight catheter. The straight catheter was left in the descending aorta (fig 1). Then the Brockenbrough catheter was removed and a $7 \mathrm{Fr}$ balloon catheter (USCI: $7 \mathrm{~mm}$ diameter when inflated) was introduced percutaneously over the long guide wire by the venous approach. This balloon catheter allowed interatrial septal dilatation and dilated the right femoral vein at the puncture site. This catheter was replaced over the long guide wire by a $9 \mathrm{Fr}$ Schneider-Medintag Grüntzig catheter (Sch-30226, Trefoil Meier, 100 $\mathrm{cm}$ long, $3 \times 12 \mathrm{~mm}$ diameter when inflated). Another type of balloon catheter (Mansfield: $18 \mathrm{~mm}$ diameter when inflated) was used in the third patient. This balloon was inserted through the mitral valve over the long guide wire without difficulty. The balloon catheter was inflated to a pressure of 400 


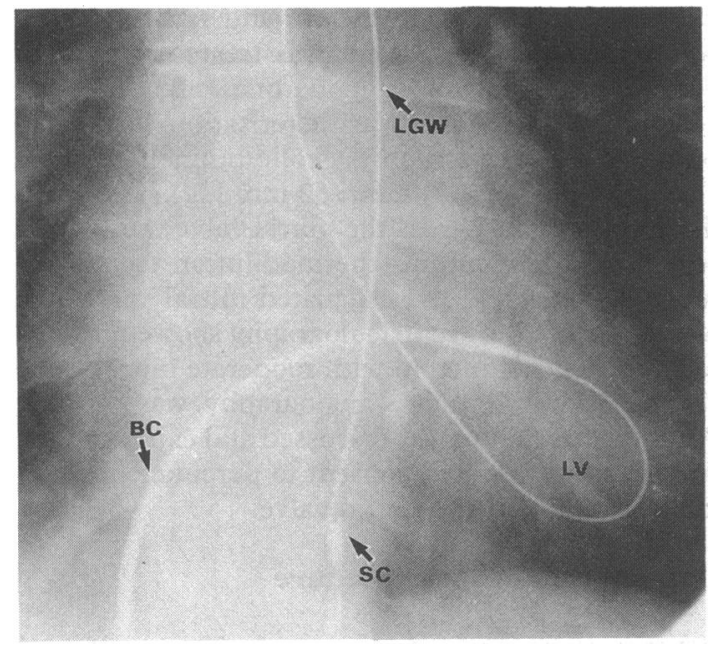

Fig 1 Cineangiogram showing a long guide wire (LGW) pushed through the Brockenbrough catheter (BC) into the left ventricle $(L V)$. The wire loop retriever was used to catch the flexible end of the long guide wire. The wire loop retriever and long guide were placed in the straight catheter (SC) positioned in the descending aorta.

$\mathrm{kPa}$ with a $50 \%$ mixture of saline solution and contrast medium after the appropriate siting of the balloon was confirmed by a mid-balloon waist (fig 2). The balloon catheter was maintained in a good position by double traction applied to both ends of the long guide wire. The inflation-deflation cycle lasted 30 seconds to one minute. Five inflation-deflation cycles were applied at intervals of 2-3 minutes.

During each cycle the aortic and pulmonary capillary wedge pressures were continuously recorded. All three patients tolerated the procedure well. At the end of the procedure the balloon dilatation catheter was withdrawn over the wire and replaced by the Brockenbrough catheter left in the left atrium. The pigtail catheter introduced by the left femoral artery was advanced into the left ventricle. The mean mitral valve gradient was measured 20 minutes after the procedure. In case 2 the gradient was measured both at rest and after infusion of isoproterenol. Cardiac output was also measured by thermodilution. A new series of right heart oximetry measurements were obtained to find evidence of an atrial shunt from left to right. Left ventriculography was performed to assess mitral regurgitation. The arterial and venous catheters were removed. Haemostasis was achieved by direct compression and the patients were monitored in the intensive care unit for 24 hours.

\section{Results}

Percutaneous balloon dilatation of the mitral valve was well tolerated by our three patients and there were no complications. All three showed an appreciable decrease in dyspnoea and increased exercise tolerance. They were rapidly discharged. The clinical improvement was confirmed two months later. Case 1 needed no treatment and case 2 had only anticoagulant treatment. The table summarises the haemodynamic data before and after balloon dilatation of the mitral valve. Dilatation reduced the mean gradient across the mitral valve and increased the calculated mitral valve area in all three patients (at rest in cases 1 and 3 and after an isoproterenol test in case 2). Right heart oximetry showed a slight left to right atrial shunt in patients 1 and 2. Figures 3-5 show left ventricular and pulmonary capillary or left atrium pressures before and after balloon dilatation.

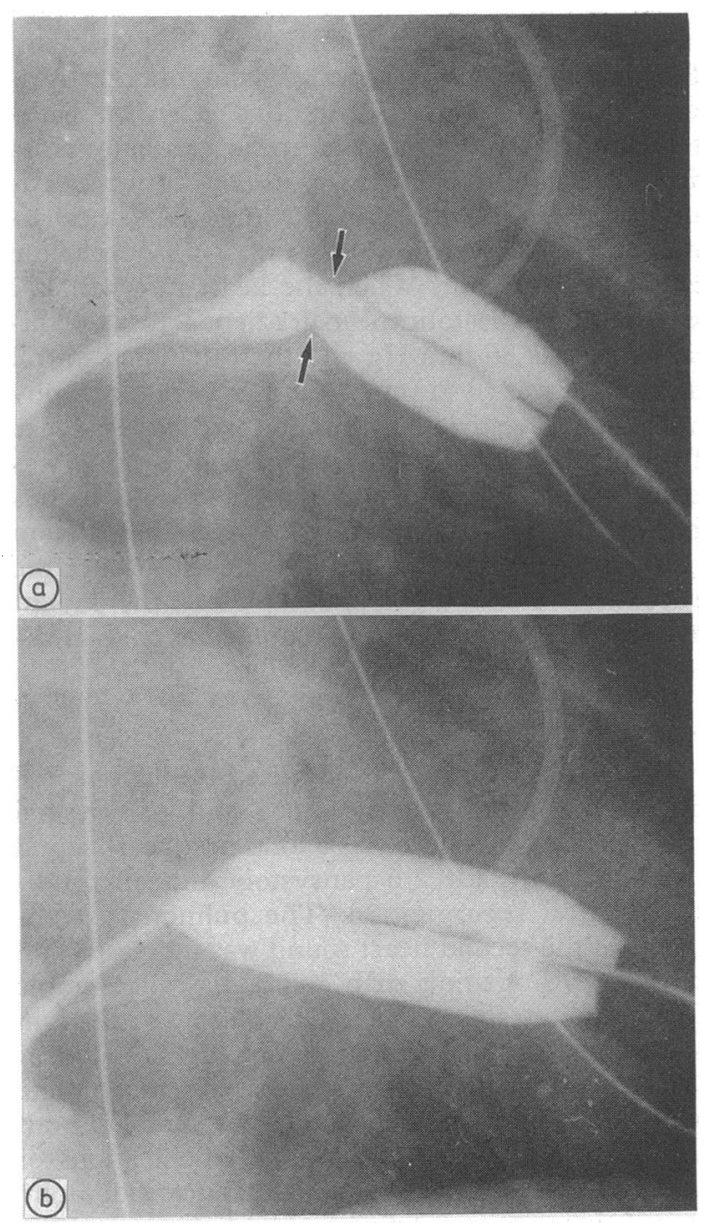

Fig 2 Cineangiogram showing a trefoil balloon $(3 \times 12$ $\mathrm{mm}$ in diameter) centred across the mitral valve. (a) The balloon was indented by the stenotic mitral valve (arrows). (b) Full inflation of the balloon. 


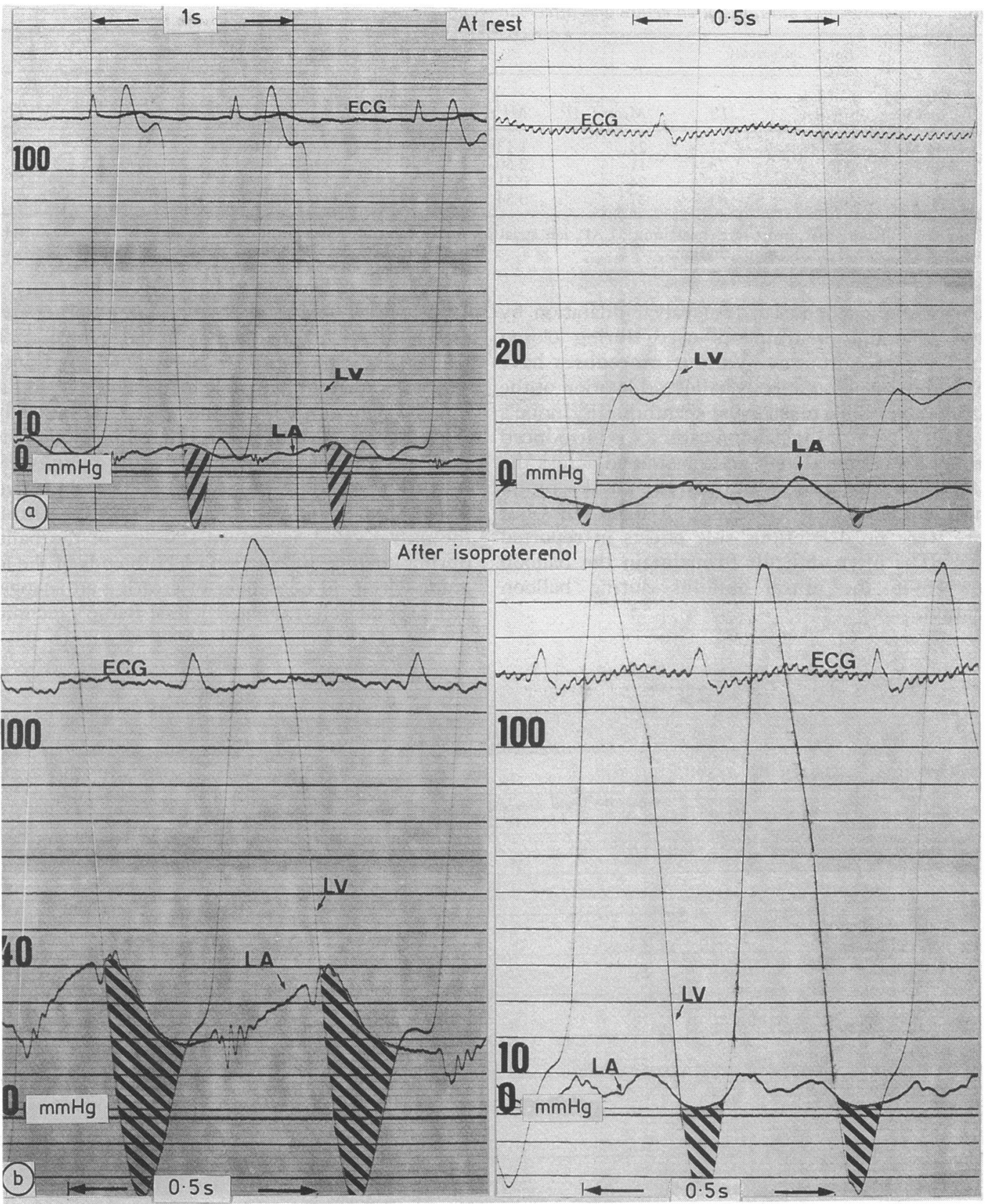

Fig 3 Simultaneous left atrial ( $L A)$ and left ventricular $(L V)$ pressures in case 1 before balloon dilatation of the mitral valve (a) and after balloon dilatation of the mitral valve (b) at rest and after isoproterenol.

\section{Discussion}

The usual treatment for mitral stenosis is surgical intervention and surgical mitral commissurotomy remains a reliable treatment for pure mitral stenosis. ${ }^{1-3}$ Recently in vitro and in vivo studies have shown the efficacy of mitral transvalvar dilatation by balloon catheter. ${ }^{71013}$ The percutaneous technique 
Table Haemodynamic data measured before and after valvotomy

\begin{tabular}{|c|c|c|c|c|c|c|c|c|c|c|}
\hline \multirow[b]{2}{*}{$\begin{array}{l}\text { Case } \\
\text { No }\end{array}$} & \multirow[b]{2}{*}{$\begin{array}{l}\text { Age (y) } \\
\text { and sex }\end{array}$} & \multicolumn{5}{|c|}{ Before valvotomy } & \multicolumn{4}{|c|}{ After valvotomy } \\
\hline & & $\begin{array}{l}\text { Cardiac } \\
\text { rhythm }\end{array}$ & $H R$ & Mean $L A P$ & $M V A$ & $M V G$ & $H R$ & Mean $L A P$ & $M V A$ & $M V G$ \\
\hline $\begin{array}{l}1 \\
2 \\
3\end{array}$ & $\begin{array}{l}44 \mathrm{M} \\
62 \mathrm{~F} \\
60 \mathrm{~F}\end{array}$ & $\begin{array}{l}\text { SR } \\
\text { AF } \\
\text { SR }\end{array}$ & $\begin{array}{r}77 \\
73 \\
157 \\
83\end{array}$ & $\begin{array}{l}25 \\
11 \\
24 \\
37\end{array}$ & $\begin{array}{l}1.13 \\
0.60 \\
0.31 \\
0.54\end{array}$ & $\begin{array}{r}23 \\
5 \\
36 \\
27\end{array}$ & $\begin{array}{r}97 \\
90 \\
176 \\
82\end{array}$ & $\begin{array}{r}18 \\
4 \\
4 \\
17\end{array}$ & $\begin{array}{l}1.80 \\
1.90 \\
1.07 \\
0.82\end{array}$ & $\begin{array}{r}10 \\
2 \\
15 \\
16\end{array}$ \\
\hline
\end{tabular}

AF, atrial fibrillation; HR, heart rate (beats/min); LAP, left atrial pressure (mm Hg); MVA, mitral valve area (cm ${ }^{2}$ ); $\mathrm{MVG}_{\mathrm{m}}$ mitral valve gradient (mm Hg); SR, sinus rhythm.

seems to be analogous to transvalvar dilatation by blunt dilatating instruments used during closed mitral commissurotomy. Various procedures have been used for percutaneous balloon dilatation of the mitral valve. The most usual technique is Inoue's procedure $^{781112}$ : the balloon catheter is introduced through the femoral vein and positioned across the mital valve after passing through the atrial septum. This commonly causes a small interatrial shunt but there were no deleterious side effects in reported cases. It is often difficult to maintain the balloon catheter in the mitral annulus during balloon inflation.
Recently Babic et al have described a new technique for balloon dilatation in mitral stenosis. ${ }^{10}$ The balloon catheter is inserted percutaneously from the left femoral artery over a long guide wire introduced into the right femoral vein, advanced transseptally to the left ventricle, and drawn out of the left ventricle, the aorta, and the femoral artery using a retriever set. According to Babic et al this procedure has several advantages: easy positioning of the balloon through the mitral valve, improved stability of the balloon during inflation by traction on both ends of the long guide wire, and no danger of creating an iatrogenic atrial septal defect. Nevertheless, Babic's technique

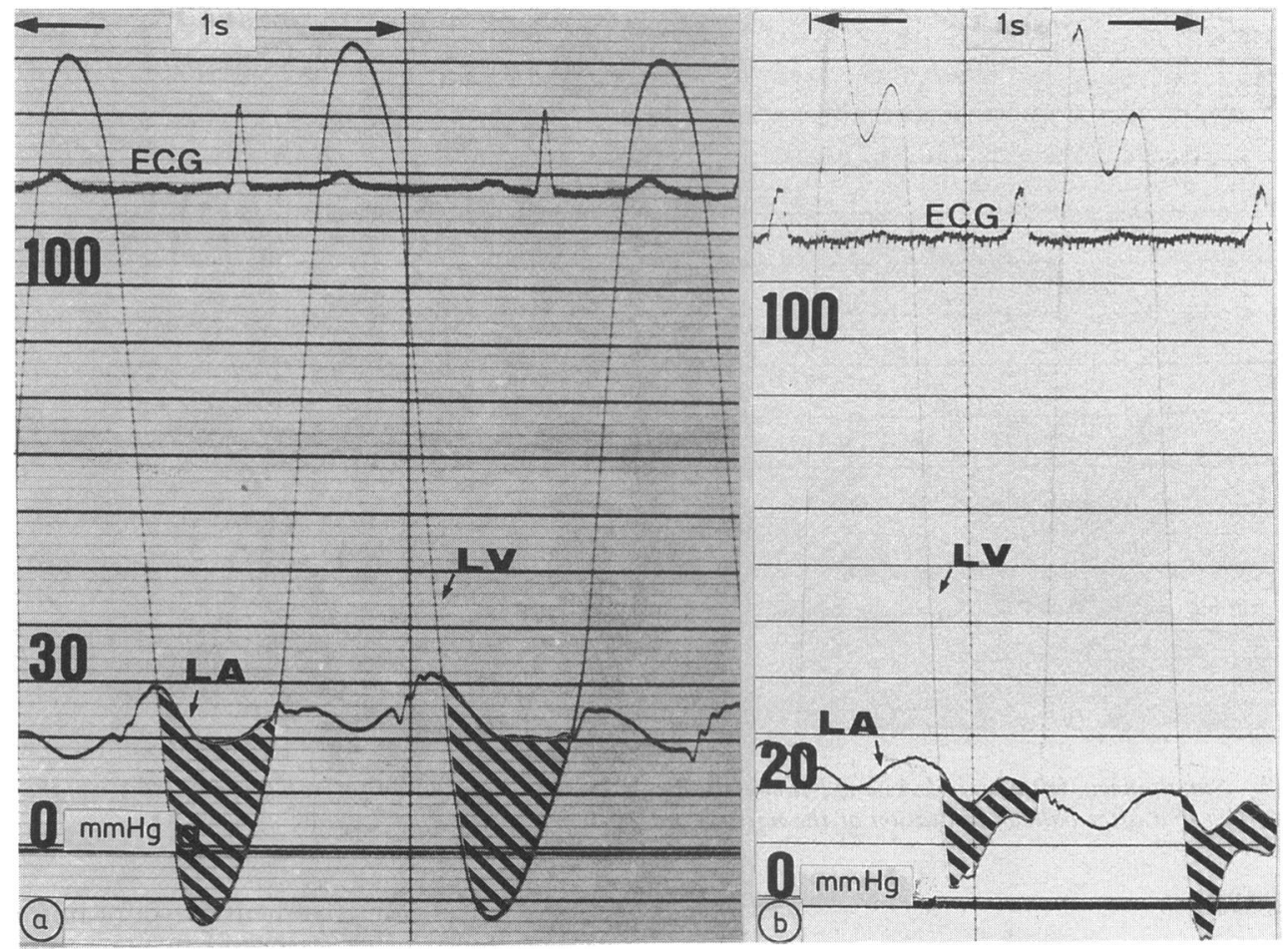

Fig 4 Simultaneous left atrial ( $L A)$ and left ventricular ( $L V)$ pressures in case 2 before balloon dilatation of the mitral valve ( $a$ ) and after balloon dilatation of the mitral valve (b). 


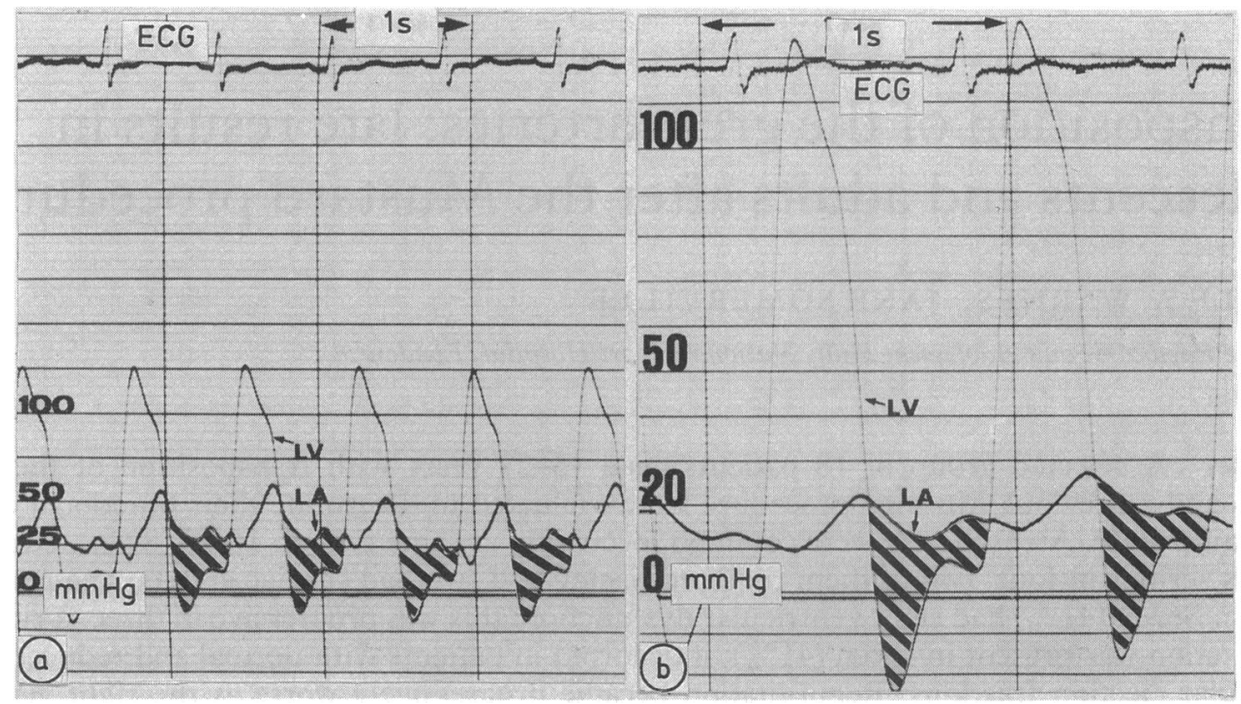

Fig 5 Simultaneous left atrial ( $L A)$ and left ventricular ( $L V)$ pressures in case 3 before balloon dilatation of the mitral valve (a) and after balloon dilatation of the mitral valve (b).

needs a femoral arterial approach with frequent local damage and considerable blood loss owing to the size of the balloon catheter. Our technique was inspired by Babic's technique but we use a femoral venous approach with transseptal technique for balloon introduction. With our technique there is also easier positioning, excellent stability of the balloon across the valve, and the option of rapidly exchanging an undersized balloon for a larger one over the long guide wire. Moreover, this technique seems to be less arrhythmogenic and, because it facilitates manual compression of the femoral vessels after the procedure, it reduces loss of blood. In our three cases the interatrial shunt after the procedure was slight or absent.

The safety and long term effectiveness of the procedure need further assessment. But the potential advantages of this technique over conventional surgical valvotomy are shorter hospital admission, lower cost, and perhaps less morbidity.

\section{References}

1 Mullin EM, Glancy DI, Higgs LM, Epstein SE. Current results of mitral operation for mitral stenosis. Clinical and hemodynamic assessments in 124 consecutive patients treated by closed commissurotomy, open commissurotomy, or valve replacement. Circulation 1972;46:298-308.

2 Heger JJ, Wann LS, Weyman AE, Dillon JC, Feigenbaum $\mathrm{H}$. Long-term changes in mitral valve area after successful mitral commissurotomy. Circulation 1979;59:443-8.

3 John S, Bashi VV, Jairaj PS, et al. Closed mitral valvotomy: early results and long-term follow-up of
3724 consecutive patients. Circulation 1983;68: 891-6.

4 Kan JS, White RI, Mitchell SE, Gardener TJ. Percutaneous balloon valvuloplasty: a new method for treating congenital pulmonary valve stenosis. $N$ Engl $J$ Med 1982;307:540-2.

5 Lababidi Z, Wu JR. Percutaneous balloon pulmonary valvuloplasty. Am J Cardiol 1983;52:560-2.

6 Lababidi Z, Jiunn-Ren W, Wall JT. Percutaneous balloon aortic valvuloplasty: results in 23 patients. $\mathrm{Am} \mathrm{J}$ Cardiol 1984;53:194-7.

7 Inoue K, Owaki T, Nakamura T, Kitamura F, Miyamoto $\mathrm{N}$. Clinical application of transvenous mitral commissurotomy by a new balloon catheter. $J$ Thorac Cardiovasc Surg 1984;87:394-402.

8 Lock JE, Khalilullah M, Shrivastava S, Bahl V, Keane JF. Percutaneous catheter commissurotomy in rheumatic mitral stenosis. N Engl J Med 1985;313:1515-8.

9 Al Zaibag M, Ribeiro P, Al Kasab S. Percutaneous transluminal valvotomy for rheumatic mitral stenosis using a double balloon technique [Abstract]. $\mathrm{Br}$ Heart $J$ 1986;55:513.

10 Babic UU, Pejcic P, Djurisic Z, Vucinic M, Grujicic SM. Percutaneous transarterial balloon valvuloplasty for mitral valve stenosis. Am J Cardiol 1986; 57:1101-4.

11 MacKay RG, Lock JE, Keane JF, Safian RD, Aroesty JM, Grossman W. Percutaneous mitral valvuloplasty in an adult patient with calcific rheumatic mitral stenosis. J Am Coll Cardiol 1986;7:1410-5.

12 Palacios IF, Lock JE, Keane JF, Block PC. Percutaneous transvenous balloon valvotomy in a patient with severe calcific mitral stenosis. J Am Coll Cardiol 1986;7:1416-9.

13 Reifart N, Nowak B, Baykut D, Bussman WD, Kaltenbach $M$. Experimental mitral valvuloplasty of fibrotic and calcified valves with balloon catheters [Abstract]. J Am Coll Cardiol 1985;5:448. 